\title{
Relation between HPV Infection and the Pathogenesis of the Extra Anogenital Squamous Cell Carcinomas in HIV Positive and Negative Patients
}

\author{
Corti M* \\ Department of Medicine, Infectious Diseases Orientation, \\ University of Buenos Aires, Argentina \\ *Corresponding author: Marcelo Corti, Department \\ of Medicine, Infectious Diseases Orientation, University \\ of Buenos Aires, Argentina
}

Received: January 21, 2017; Accepted: February 16, 2017; Published: February 17, 2017

\begin{abstract}
The most extensive and well demonstrated evidence about the association between Human Papillomavirus (HPV) oncogenic type's infection and neoplasm's include the cervical and the anal squamous cell carcinomas. However, the more recent evidence suggested that HPV is involved in the pathogenic of malignancies located at many different sites. The incidence of head and neck cancers, especially those which involve the orpharyngeal anatomic region has actually been increasing. HIV co-infection appears to be as an additional risk factor to develop premalignant and invasive carcinomas of the head and neck, including esophageal Squamous Cell Carcinomas (SCC). In all these cases, HPV demonstrates a specific tropism for cutaneous and mucosal epithelia. In consequence, in all regions with squamous cell epithelium, we can found neoplasm's related with HPV chronic infection. Oncogenic HPV types, especially 16 and 18, appear to target the basal cells of squamous epithelium and increase the risk to develop dysplastic lesions and, eventually, premalignant and malignant lesions. One of the most important risk factor for HPV infection, especially, in men who have sex with men, appears to be HIV co-infection. There is a high prevalence of HPV in HIV positive men; this is especially important in the anal region but it is beginning to be important in warts lesions located in the oral cavity, oropharynx, hipopharynx, larynx and oesophageus. Patients with HPV-oropharyngeal SCC generally have a better response to chemotherapy and radiotherapy in comparison with those with HPV negative tumors.
\end{abstract}

Keywords: Human Papillomavirus; Human Immunodeficiency Virus; Squamous Cell Carcinomas; Head and Neck

\section{Introduction}

The widespread use of highly active antiretroviral therapy (HAART) since 1996 has reduce dramatically the incidence of opportunistic infections and certain AIDS-defining neoplasm's in Human Immunodeficiency Virus (HIV) seropositive patients [1]. The incidence of Kaposi's sarcoma and certain subtypes of NonHodgkin's lymphomas (especially primary central nervous system lymphoma) declined 70\% [2]. However, HIV-infected people also have an increased risk of non-AIDS defining cancers including those associated with previous viral co-infections as anal cancer related with human papillomavirus (HPV) infection, liver cancer associated with hepatitis B and C viruses and Hodgkin's lymphoma associated with Epstein-Barr virus infection. Also, lung cancer shows a high incidence in the HIV/AIDS population, related with the high incidence of cigarette smoking [3,4]. The high incidence of these neoplasms is independent of the widespread use of HAART and the immune reconstitution.

Human Papillomavirus (HPV) is the etiologic agent of the most common sexually transmitted infection, named as genital warts or condylomata [5]. There are more than $130 \mathrm{HPV}$ types; some of them are classified as of high-risk according with the potential oncogenic role related with persistent infection [6].
The association between HPV and anogenital cancers has been well described; HPV is responsible for more than $95 \%$ of cervical cancers; $85 \%$ of anal intraepithelial squamous cell carcinoma (SCC); $65 \%$ of vaginal; $50 \%$ of vulvar and $35 \%$ of penile carcinomas. Additionally, HPV is related with the pathogenic of $45 \%$ to $90 \%$ of oropharyngeal SCC $[7,8]$. Generally these malignancies appear after a long period of HIV infection; previous studies showed that HAART has not reduced the prevalence of HPV infection and has not declined the incidence of high grade anal or cervical squamous epithelial lesions [9].

\section{Pathogenic of Squamous Cell Carcinomas of the Head and Neck}

Natural history of oral HPV infection include the transformation of normal epithelium of the oropharynx to high grade dysplasia, in situ carcinoma and, finally, invasive squamous cell carcinoma [10]. The prevalence of oncogenic subtypes of HPV (16/18) in oral cavity lesions is high in dysplastic lesions [11].

\section{HPV and Squamous Cell Carcinomas of the Head and Neck}

The relation between HPV and head and neck cancers was first described relatively recently by Syrjänen in 1983 [12-14]. This role of HPV in head and neck malignant tumors has demonstrated in the 
oral cavity, pharyngeal and laryngeal SCC. HPV is detected in 23\% to $35 \%$ of all head and neck SCC, especially cancers that arising the oropharynx, in which HPV have been identified in $45 \%$ to $90 \%$ of all the cases [15-17]. The lingual and palatine tonsils are the most common sites where HPV was detected. With less frequency, HPV was identified in SCC of the oral cavity and the larynx. HPV 16 and, with less frequency, HPV 18, were identified in these carcinomas [18]. Similar to cervical cancer, HPV 16 is the most common type detected in $68 \%$ to $87 \%$ of all head and neck SCC $[8,19]$.

\section{Oral Squamous Cell Carcinomas and HPV Infection}

The incidence of tonsillar and neoplasms of the base of the tongue is increasing in direct relation with HPV infection. Also, in these tumors, HPV 16 is the most frequent subtype identified ( $86 \%$ of cases) [20-22]. Increased number of oral sex partners have been associated with an increased risk of HPV infection; a similar situation occurs with vaginal or anal HPV-related lesions [23], and increases the risk of oropharyngeal SCC $[24,25]$. Additionally, HIV infection is an independent risk factor to a high prevalence of different grades of HPV lesions. Patients seropositive for HIV had a significantly high prevalence of oral HPV infection $(25,3 \%$ vs $7,6 \%$; $<<0,001)$ and oral high-risk of HPV serotypes $(13,7 \%$ vs $4,5 \%$; p 0,001$)$ in comparison with HIV-negative individuals [26]. These findings suggest that immunodeficiency associated with HIV infection may increases the risk of oral HPV infection, and secondary, to oral SCC [27-29]. Clinically, HPV-associated oral SCC have different clinical and histopathological findings and an improve prognosis. These patients are typically younger, male, non-smokers and nondrinkers [30,31]. HPV-positive tumors are more frequently poorly differentiated and with a basaloid morphology in comparison with HPV-negative cancers [31,32]. Finally, patients with HPV oral SCC positive tumors generally presents with advanced disease and TNM stage $[33,34]$. Improved prognosis for HPV-positive patients with oral SCC presented with locally advanced disease could be achieved with a treatment based on chemotherapy and radiotherapy [35]. Also, a recent case report, described 2 patients with HPV-related anal SCC who subsequently developed oral SCC [36]. Generally, these secondary primary cancer occurs in patients with history of HPV related SCC, but originated in a different site of the first malignant lesion.

Also, Licitra et al [37] observed that HPV-positive patients with oral SCC treated primarily with surgical resection followed by adjuvant radiotherapy had a significantly improved 5-year overall survival rate $(79 \%$ vs $46 \% ; \mathrm{p}=0,00018)$. However, in a retrospective analysis at the Mayo Clinic, no significant survival difference was seen between HPV-positive and negative patients treated with surgery followed by radiotherapy [38]. Another retrospective studies, with transoral robotic surgery showed no differences in outcome according to HPV status $[39,40]$.

\section{HPV Infection and Esophageal Squamous Cell Carcinoma}

The first reports that suggested a relationship between esophageal SCC and HPV-oncogenic subtypes infection date to 1982 [41]. Syrjänen was the first to suggest the association of HPV with both benign and malignant squamous cell lesions of the esophagus [42]. One of the most important characteristics of SCC of the esophagus is the wide variation in the incidence of the disease in different regions of the world [43].

Several risk factors have been described related with the development of esophageal SCC. Chemical or toxic substances, cigarette smoke, excessive alcohol intakes, and nutritional deficits of vitamins and other elements, have been linked to this malignancy [44,45]. More later, Syrjänen [42] suggested the possible role of HPV infection with the development of this neoplasm. Multiple studies detected HPV-DNA in esophageal carcinomas using different in situ hybridization (ISH) techniques and polymerase chain reaction (PCR). HPV detection rates ranged between 23\% using ISH and 15\% by PCR en esophageal cancers [42].

Similar to other SCC of the head and neck, oncogenic subtypes of $\mathrm{HPV}$, especially 16 , have a stronger relationship with the development of esophageal SCC. Additionally, the presence of serum antibodies against HPV-16 E7 oncoprotein should be a predictive factor of esophageal SCC [46]. Also similarity to other SCC of the head and neck, some data suggested that both E6 and E7 oncogenic proteins interfere with the cell cycle regulation and play an important role in the pathogenesis of esophageal SCC $[42,46]$.

\section{Conclusion}

In conclusion, it is well demonstrated that HPV oncogenic subtypes are involvement in the pathogenesis of both, benign (papillomas or condylomas) and malignant (carcinomas) of the head and neck, including oral and esophageal lesions. HPV-DNA was detected by ISH and PCR in premalignant lesions and cancers in both, general and HIV infected patients. The experimental data suggest that similar pathogenic mechanisms to those occur in cervical and anal SCC is also implicated in head and neck HPV-associated SCC.

A higher suspicion is necessary to achieve an early diagnosis and to improve the survival of patients with head and neck carcinomas associated with HPV, especially in HIV-seropositive patients. A carefully evaluation of infiltrative or tumoral lesions of these anatomic region is necessary in this kind of patients. Finally, these patients show a lower risk of second primary cancers.

\section{References}

1. Patel P, Hanson DL, Sullivan PS, Novak RM, Moorman AC, Tong TC, et al. Adult and Adolescent Spectrum of Disease Project and HIV Outpatient Study Investigators. Incidence of types of cancer among HIV-infected persons compared with the general population in the United States, 1992-2003. Ann Intern Med. 2008; 148: 728-736.

2. Silverberg MJ, Chao C, Leyden WA, Tang B, Horberg MA, Klein D, et al. Abrams DI. HIV infection and the risk of cancers with and without a know infection cause. AIDS. 2009; 23: 2337-2345.

3. Engels EA, Pfeiffer RM, Goeders JJ, Virgo P, McNeel TS, Scoppa SM, et al For the HIVIAIDS Cancer Match Study. Trends in cancer risk among people with AIDS in the United States 1980-2002. AIDS. 2006; 20: 1645-1654.

4. Shields MS, Pfeiffer RM, Gail MH, Hall HI, Li J, Chaturvedi AK, et al. Cance burden in the HIV-infected population in the United States. J Natl Cancer Inst. 2011; 103: 1-10.

5. Klingelhutz AJ, Roman A. Cellular transformation by human papillomaviruses: lessons learned by comparing high- and low-risk viruses. Virology. 2012; 424: 77-98.

6. zur Hausen H. Papillomaviruses in the causation of human cancers-a brief 
historical account. Virology. 2009; 384: 260-265.

7. De Vuyst H, Clifford GM, Nascimento MC, Madeleine MM, Franceschi S. Prevalenceand type distribution of human papillomavirus in carcinoma and intraepithelial neoplasia of the vulva, vagina and anus: a meta-analysis. Int J Cancer. 2009; 124: 1626-1636.

8. Kreimer AR, Clifford GM, Boyle P, Franceschi S. Human papillomavirus types in head and neck squamous cell carcinomas worldwide: a systematic review. Cancer Epidemiol Biomarkers Prev. 2005; 14: 467-475.

9. Severini A. Anal intraepithelial neoplasia in men living with HIV in the era of highly active antiretroviral therapy. Clin Infect Dis. 2011; 52: 1182-1183.

10. Fakhry C, Sugar E, D'Souza G, Gillison M. Two-week versus six-month sampling interval in a short-term natural history study of oral HPV infection in an HIV-positive cohort. PLoS One. 2010; 5: 11918

11. Laverty CR, Booth N, Hills E, Cossart Y, Wills EJ. Noncondylomatous war virus infection of the postmenopausal cervix. Pathology. 1978; 10: 373-378.

12. Syrjanen K, Vayrynen M, Castren O, Mantyjarvi R, Pyrhonen S, Yliskoski M. Morphological and immunohistochemical evidence of Human Papilloma Virus (HPV) involvement in the dysplastic lesions of the uterine cervix. Int $\mathrm{J}$ Gynaecol Obstet. 1983; 21: 261-269.

13. Syrjanen K, Syrjanen S, Lamberg M, Pyrhonen S, Nuutinen J. Morphological and immunohistochemical evidence suggesting human papillomavirus (HPV) involvement in oral squamous cell carcinogenesis. Int J Oral Surg. 1983; 12: 418-424.

14. Syrjanen KJ, Syrjanen SM, Lamberg MA, Pyrhonen S. Human papillomavirus (HPV) involvement in squamous cell lesions of the oral cavity. Proc Finn Dent Soc. 1983; 79: 1-8.

15. Lohavanichbutr P, Houck J, Fan W, Yueh B, Mendez E, Futran N, et al. Genomewide gene expression profiles of HPV-positive and HPV negative oropharyngeal cancer: potential implications for treatment choices. Arch Otolaryngol Head Neck Surg. 2009; 135: 180-188.

16. Fischer CA, Zlobec I, Green E, Probst S, Storck C, Lugli A, et al. Is the improved prognosis of p16 positive oropharyngeal squamous cell carcinoma dependent of the treatment modality? Int J Cancer. 2010; 126: 1256-1262.

17. Mendenhall WM, Logan HL. Human Papillomavirus and Head and Neck Cancer. Am J Clin Oncol. 2009; 32: 535-539.

18. Braemer Lajer C, Von Buchwald C. The role of human papillomavirus in head and neck cancer. APMIS. 2010; 118: 510-519.

19. Munoz N, Bosch FX, de Sanjose S, et al. International Agency for Research on Cancer Multicenter Cervical Cancer Study Group. Epidemiologic classification of human papillomavirus types associated with cervical cancer N Engl J Med. 2003; 348: 518-527.

20. Attner P, Du J, Na"sman A et al. The role of human papillomavirus in the increased incidence of base of tongue cancer. Int J Cancer. 2010; 126: 2879 2884

21. Chaturvedi AK, Engels EA, Anderson WF, et al. Incidence trends for human papillomavirus-related and -unrelated oral squamous cell carcinomas in the United States. J Clin Oncol. 2008; 6: 612-619.

22. Hammarstedt $\mathrm{L}$, Lindquist $\mathrm{D}$, Dahlstrand $\mathrm{H}$, et al. Human papillomavirus as a riskfactor for the increase in incidence of tonsillar cancer. Int J Cancer. 2006 119: 2620-2623.

23. Corti M, Villafañe MF, Priarone MM, Vittar N, Lewi D, Marona E, et al. Ana squamous cell carcinoma in HIVIAIDS patients in the HAART era: Report of 8 cases and literature review. Acta Gastroenterol Latinoam. 2014; 44: 305-310.

24. Hansson BG, Rosenquist K, Antonsson A, et al. Strong association between infection with human papillomavirus and oral and oropharyngeal squamous cell carcinoma: a population-based case-control study in southern Sweden. Acta Otolaryngol. 2005; 125: 1337-1344

25. D'Souza G, Kreimer AR, Viscidi R, et al. Case-control study of human papillomavirus and oropharyngeal cancer. N Engl J Med. 2007; 356: 19441956.

26. Kreimer AR, Alberg AJ, Daniel R, et al. Oral human papillomavirus infection in adults is associated with sexual behavior and HIV serostatus. J Infect Dis.
2004; 189: 686-698.

27. Gillison ML, Broutian T, Pickard RK, et al. Prevalence of oral HPV infection in the United States, 2009-2010. JAMA. 2012; 307: 693-703.

28. Kreimer AR, Bhatia RK, Messeguer AL, Gonzalez P, Herrero R, Giuliano AR. Oral human papillomavirus in healthy individuals: a systematic review of the literature. Sex Transm Dis. 2010; 37: 386-391.

29. D'Souza G, Agrawal Y, Halpern J, Bodison S, Gillison ML. Oral sexual behaviors associated with prevalent oral human papillomavirus infection. J Infect Dis. 2009; 199: 1263-1269.

30. Chaturvedi AK, Engels EA, Pfeiffer RM, et al. Human papillomavirus and rising oropharyngeal cancer incidence in the United States. J Clin Oncol. 2011; 29: 4294-4301.

31. Gillison ML, Koch WM, Capone RB, et al. Evidence for a causal association between human papillomavirus and a subset of head and neck cancers. J Natl Cancer Inst. 2000; 92: 709-720.

32. Begum S, Westra WH. Basaloid squamous cell carcinoma of the head and neck is a mixed variant that can be further resolved by HPV status. Am J Surg Pathol. 2008; 32: 1044-1050.

33. Hafkamp HC, Manni JJ, Haesevoets A, et al. Marked differences in survival rate between smokers and nonsmokers with HPV 16-associated tonsillar carcinomas. Int J Cancer. 2008; 122: 2656-2664.

34. Goldenberg D, Begum S, Westra WH, et al. Cystic lymph node metastasis in patients with head and neck cancer: an HPV-associated phenomenon. Head Neck. 2008; 30: 898-903

35. Zandberg DP, Bhargava R, Badin S, Cullen KJ. The Role of Human Papillomavirus in Nongenital Cancers. Cancer J Clin. 2013; 63: 57-81.

36. Chaiyachati K, Cinti SK, Kauffman CA, et al. HIV-infected patients with ana carcinoma who subsequently developed oral squamous cell carcinoma: report of 2 cases. J Int Assoc Phys AIDS care. 2008; 7: 306-310.

37. Licitra L, Perrone F, Bossi $P$, et al. High-risk human papillomavirus affects prognosis in patients with surgically treated oropharyngeal squamous cell carcinoma. J Clin Oncol.2006; 24: 5630-5636.

38. Ukpo OC, Pritchett CV, Lewis JE, Weaver AL, Smith DI, Moore EJ. Human papillomavirus-associated oropharyngeal squamous cell carcinomas: primary tumor burden and survival in surgical patients. Ann Otol Rhinol Laryngol. 2009; 118: 368-373.

39. Cohen MA, Weinstein GS, O'Malley BW Jr, FeldmanM, QuonH. Transora robotic surgery and human papillomavirus status: oncologic results. Head Neck. 2011: 33: 573-580.

40. Quon H, Cohen MA, Montone KT, et al. Transoral robotic surgery and adjuvant therapy for oropharyngeal carcinomas and the influence of p16(INK4a)on treatment outcomes [published online ahead of print July 20 , 2011]. Laryngoscope. 2013; 123: 635-640.

41. Syrjanen KJ. Histological changes identical to those of condylomatous lesions found in esophageal squamous cell carcinomas. Arch Geschwulstforsch. 1982; 52: 283-292

42. Syrjänen KJ. HPV infections and oesophageal cancer. J Clin Pathol. 2002; 55: 721-728.

43. Ferlay J, Bray F, Pisani P, et al. GLOBOCAN 2000: cancer incidence, mortality and prevalence worldwide, Version 1.0. IARC Cancer Base No. 5. Lyon: IARC Press. 2001.

44. Syrjänen K, Chang F, Syrjänen S. Infectious agents as etiological factors in esophageal carcinogenesis. In: Tahara E, Sugimachi K, Oohara T. eds. Recent advances in gastroenterological carcinogenesis I. Bologna: Monduzzi Editore. 1996: 29-43

45. Chang F, Syrjänen SM, Wang L, et al. Infectious agents in the etiology of esophageal cancer. Gastroenterology. 1992; 103: 1336-1348.

46. Guo F, Liu Y, Wang X, He Z, Weiss NS, Madeleine MM, et al. Human Papillomavirus Infection and Esophageal Squamous Cell Carcinoma: A Case-Control Study. Cancer Epidemiol Biomarkers Prev. 2012; 21: 780-785. 